\title{
Particle size of LDL is affected by the National Cholesterol Education Program (NCEP) step II diet in dyslipidaemic adolescents
}

\author{
Leila Azadbakht, Parvin Mirmiran, Mehdi Hedayati, Ahmad Esmaillzadeh, Nilufar Shiva and \\ Fereidoun Azizi* \\ Endocrine Research Center, Shaheed Beheshti University of Medical Sciences, P.O. Box 19395-4763, Tehran, Iran \\ (Received 6 March 2006 - Revised 8 August 2006 - Accepted 31 August 2006)
}

\begin{abstract}
The objective was to determine the effects of the National Cholesterol Education Program (NCEP) step II diet on LDL and HDL particle size in dyslipidaemic adolescents. Forty-four dyslipidaemic adolescents, aged 10-18 years, participated in this case-control study. The control diet was a diet similar to what most Tehranian adolescents eat. NCEP step II diet was a diet with $30 \%$ of energy as total fat, less than $7 \%$ saturated fat, less than $200 \mathrm{mg}$ cholesterol/d, less than $15 \%$ of energy as MUFA and less than $10 \%$ as PUFA. Lipoprotein particle size was the major outcome variable, which was measured after 3 months of intervention. Comparison was made by the repeated measurement ANOVA. The mean BMI was $26 \cdot 3$ $(\mathrm{SD} 4.2) \mathrm{kg} / \mathrm{m}^{2}$. There were no significant changes in weight or physical activity in the two groups during the study. The NCEP diet resulted in higher reduction in total cholesterol ( -13 (SD 4) v. -2 (SD 0.3) $\mathrm{mg} / \mathrm{dl}, P<0 \cdot 001$ ) and LDL ( -9 (SD 2) v. 3 (SD 0.6) mg/dl, $P<0 \cdot 01$ ), and higher increase in size of the LDL (1.7 (SD 0.4) v. 0.1 (SD 0.4) nanometer, $P<0.001$ ). HDL particle size did not change significantly. NCEP step II diet had a favourable effect on the LDL particle size. The related mechanism needs to be studied in future experimental designs.
\end{abstract}

National Cholesterol Education Program (NCEP): Adolescents: LDL: Lipoprotein particle size

Epidemiological, pathological, clinical and genetic studies give evidence that atherosclerosis begins during childhood and the serum lipid profile concentration in childhood is a useful parameter in predicting adult dyslipoproteinaemia (Boreham et al. 1993). It has been shown that mean cholesterol concentrations in children of many countries have increased in recent years (Plaza et al. 1989), and hypercholesterolaemia in these children is approaching values found in populations with high incidence of ischemic heart disease (Akerblom et al. 1984). According to the results of the Tehran Lipid and Glucose Study (Azizi et al. 2000), $22 \%$ of the Iranian population of children and adolescents had LDL cholestrol (LDL-C) values between 110 and $129 \mathrm{mg} /$ $\mathrm{dl}$ and $17 \%$ had values $\geq 130 \mathrm{mg} / \mathrm{dl}$ (Azizi et al. 2001). Dietary modification to lower LDL-C is the primary strategy for reducing CVD risk (Sempos et al. 1993). The National Cholesterol Education Program (NCEP) step II recommends reducing saturated fat intake to $<7 \%$ of energy in the initial management of individuals with hypercholesterolaemia (Sempos et al. 1993). It has been mentioned that the NCEP step II diet produced a desirable lipoprotein response (Schaefer et al. 1995; Flynn et al. 1999). Of course, different responses in other studies may be due to positive family history of heart disease (Knutsen \& Knutsen, 1991; Mietus-Snyder et al. 1993). It has been indicated that the NCEP step II diet significantly decreases triacylglycerolrich lipoprotein and plasma apo $\mathrm{A}_{\mathrm{IV}}$ concentrations (Sun et al. 2001). A significant decrease in HDL subfraction 2 cholestrol has also been mentioned in other studies (Wood et al. 1991; Walden et al. 2000). Circulating LDL-C concentrations are a well-stablished risk factor for $\mathrm{CHD}$, but many individuals with CHD have normal or only slightly elevated LDL-C (Kannel \& Wilson, 1992). A relation between plasma concentrations of small dense LDL and carotid intima media thickness has been shown in adults (Skoglund-Andersson et al. 1999) and the association of these particles and cardiovascular risk factors has also been mentioned in children (Kojima et al. 2005). These associations may be explained by atherogenicity of small dense LDL due to increased plasma residence time, susceptibility to oxidation and binding affinity for proteoglycans in the subendothelial space (Lamarche et al. 1999). LDL particles are heterogeneous with respect to size, density composition and physicochemical properties (Lindgren et al. 1969; Chapman et al. 1988). Discrete subspecies of LDL, based on particle size, were first described over 20 years ago (Krauss \& Burke, 1982), but not enough attention has been given to the influence of dietary habits of adolescents on the size of lipoproteins. A significant proportion of the cardioprotective properties of HDL has been attributed to the largest and less dense HDL subfraction 2 particles (Lamarche et al. 1997). Therefore, we aim to determine the effects of the NCEP step II diet on LDL and HDL particle size in dyslipidaemic adolescents.

\footnotetext{
Abbreviations: LDL-C, LDL cholestrol; NCEP, National Cholesterol Education Program.

* Corresponding author: Dr Fereidoun Azizi, fax +98 21 22402463, email Azizi@erc.ac.ir
} 


\section{Subjects and methods}

\section{Subjects}

The present study includes adolescents aged 10-18 years recruited from among participants of the Tehran Lipid and Glucose Study (Azizi et al. 2000), with hypercholesterolaemia (total cholesterol $\geq 170 \mathrm{mg} / \mathrm{dl}$ and LDL-C $\geq 110 \mathrm{mg} / \mathrm{dl}$; Krummel, et al. 2004). Each adolescent was asked to complete a personal health and medical history questionnaire that served as a screening tool. Patients were excluded if they had psychiatric problems, took any medication affecting nutrient metabolism, blood lipids and blood pressure, or any vitamin and mineral supplements and antacids containing magnesium or calcium. All the adolescents were evaluated for thyroid function by the measurement of serum thyroid-stimulating hormone (TSH), triiadothyronine $\left(\mathrm{T}_{3}\right)$ and tetraiodothyronine $\left(\mathrm{T}_{4}\right)$ and those with any liver or renal diseases were excluded. Sixty adolescents were assessed for eligibility in the study. Fourteen subjects were ineligible because they did not meet protocol criteria; forty-six patients were randomly assigned to the two groups, the control and the NCEP step II diet, using a computer-generated random number sequence. Twenty-three of the assigned received a NCEP step II diet and the other twenty-three received a control diet. Two adolescents dropped out (one from the NCEP step II and one from the control group). Other patients completed the study and were included in the data analysis (forty-four patients). The nutritionist who prescribed the diets had to be aware of the group assignment. Laboratory staff were not aware of the patients' group assignments. Diets were offered according to specific individualized programmes at the end of run-in (baseline). The proposal of the present study was approved by the research council of the Endocrine Research Center of Shaheed Beheshti University of Medical Sciences and informed written consent was obtained from each subject.

\section{Control diet}

The control group was not given a diet prescription and was simply instructed to 'eat as usual'. Their eating patterns reflected the consumption of macronutrients, fruit, vegetables and dairy products, typical of what many Tehranians eat (carbohydrates, 50-60\%; proteins, 15-20\%; and total fat $<30 \%$; most of fat specified as saturated, using two to three servings of fruit, three servings of vegetables, one serving of dairy) (Mirmiran et al. 2005).

\section{National Cholesterol Education Program step II diet}

The NCEP step II diet had $30 \%$ of energy as total fat, less than $7 \%$ saturated fat, less than $200 \mathrm{mg}$ cholesterol/d, less than $15 \%$ of energy as MUFA and less than $10 \%$ as PUFA. Table 1 shows the nutrient and food groups consumed during the intervention period.

We determined the energy needs for each person individually according to the equation from the Institute of Medicine, Food \& Nutrition Board (2002). Energy was calculated to maintain the weight and weight loss or weight gain was prevented. The patients were visited every 2 weeks, each session for a patient being $45-60 \mathrm{~min}$. They were in touch with the nutritionist by telephone every day; behavioural
Table 1. Nutrient content and food group servings of menus for the control diet and the National Cholesterol Education Program (NCEP) step II diet

\begin{tabular}{|c|c|c|c|c|}
\hline \multirow[b]{2}{*}{ Nutrient content $†$} & \multicolumn{2}{|c|}{$\begin{array}{l}\text { Control dietł } \\
\quad(n 22)\end{array}$} & \multicolumn{2}{|c|}{$\begin{array}{l}\text { NCEP step II } \\
\operatorname{diet\S }(n \text { 22) }\end{array}$} \\
\hline & Mean & SEM & Mean & SEM \\
\hline Energy $(\mathrm{kJ})$ & 8481 & 100 & 842 & 96 \\
\hline Protein (\% of energy) & 15 & 0.4 & 15 & 0.3 \\
\hline Total fat (\% of energy) & 30 & 0.6 & 29 & 0.5 \\
\hline Saturated fat (\% of energy) & 14 & 0.6 & 7 & $0.5^{\star}$ \\
\hline PUFA ( $\%$ of energy) & 7 & 0.6 & 8 & 0.6 \\
\hline MUFA (\% of energy) & 9 & 0.4 & 14 & $0 \cdot 6^{\star}$ \\
\hline Cholesterol (mg) & 311 & 10 & 183 & $7^{\star}$ \\
\hline Carbohydrate ( $\%$ of energy) & 55 & 1 & 56 & 1 \\
\hline Fibre $(\mathrm{g})$ & 10 & 1 & 29 & $3^{*}$ \\
\hline Potassium (mg) & 1400 & 149 & 1900 & $174^{\star}$ \\
\hline Calcium (mg) & 700 & 74 & 801 & $83^{*}$ \\
\hline Magnesium (mg) & 180 & 4 & 201 & 5 \\
\hline \multicolumn{5}{|l|}{ Food groups (servings/d) } \\
\hline Fruit & $2 \cdot 5$ & 0.1 & 4 & $0 \cdot 1^{*}$ \\
\hline Vegetable & 3.0 & 0.1 & 4 & 0.1 \\
\hline \multicolumn{5}{|l|}{ Grains } \\
\hline Total & 8 & 0.1 & 8 & 0.1 \\
\hline Whole & 1 & 0.1 & 3 & $0.1^{*}$ \\
\hline Low-fat dairy & 0.5 & 0.1 & $2 \cdot 5$ & $0.1^{*}$ \\
\hline Regular-fat dairy & 0.5 & 0.1 & 0 & 0 \\
\hline Nut seeds and legumes & 0.1 & 0.1 & 0.9 & $0 \cdot 1^{*}$ \\
\hline Red meat & 1 & 0.1 & 0.5 & 0.1 \\
\hline Poultry and fish & 0.5 & 0.1 & 1 & 0.1 \\
\hline Fat and oils & 7 & 0.1 & 3 & $0.1^{*}$ \\
\hline Sweets & 5.5 & 0.2 & $2 \cdot 5$ & $0.1^{*}$ \\
\hline
\end{tabular}

Mean values were significantly different from those of the control diet: ${ }^{*} P<0.04$. $\dagger$ Nutrient contents were calculated according to Nutritionist III version 7.0. $\ddagger$ Diet similar to what most Tehranian adolescents usually eat.

$\S$ Diet contains $30 \%$ of energy as total fat, less than $7 \%$ saturated fat, less than $200 \mathrm{mg}$ cholesterol/d, less than $15 \%$ of energy as MUFA and less than $10 \%$ as PUFA.

and psychological counselling was offered. The nutritionist explained the benefits of each diet for patients, emphasizing that if they continued this diet, related metabolic abnormalities could be controlled. The diets were individually prescribed using a calorie count system and an exchange list was given to each patient for exchanging food items and counting calories. A nutritionist educated subjects on how to use the exchange list and write food diaries. Every patient had to bring his or her $3 \mathrm{~d}$ diet records every 2 weeks and the diaries were reviewed by study staff. A $7 \mathrm{~d}$ menu cycle with twenty-one meals at six energy levels (5021, 6276, 7531, 8368, 9623, $10460 \mathrm{~kJ}(1200,1500,1800,2000$, $2300,2500 \mathrm{kcal})$ ) was developed for each diet.

To maximize treatment fidelity, group discussions were conducted monthly. In these sessions the food items that should be eaten in each diet were emphasized and intervention patients received education on reducing dietary energy and diet compliance; patients were encouraged to follow their diets. The investigators randomly took part in the counselling sessions, controlling the messages that the nutritionist was giving to each group and randomly questioning the patients about their diets. The patients' compliance was assessed by analysing the three food record diaries every 2 weeks and the attendance at meetings and monthly visits. 


\section{Study procedures}

After the 3 weeks of run-in, the clinical centre followed patients every 2 weeks for the 3 months duration of interventional feeding. We conducted a run-in to homogenize the consumption of macronutrients and base of diets. The measurements were taken every 2 weeks during the 3 months of the study period except for blood tests, which were repeated every 6 weeks, both in the control and NCEP groups.

Participants were requested not to change their habitual levels of physical activity for the duration of the study. To compute intake at baseline and during intervention, $3 \mathrm{~d}$ records were used for each month. Nutrients were analysed by Nutritionist III software, version 7.0 (N-Squared computing, Salem, OR, USA), which was modified for Iranian foods.

\section{Measurements}

Weight was measured using digital scales and recorded to the nearest $0.1 \mathrm{~kg}$ while the subjects were minimally clothed without shoes. Height was measured using a tape measure with subjects in a standing position, without shoes, while the shoulders were in a normal state.

Twelve-hour fasting blood samples were collected in tubes containing $0.1 \%$ EDTA and then centrifuged at $4{ }^{\circ} \mathrm{C}$ and $500 \mathrm{~g}$ for $10 \mathrm{~min}$ to separate the plasma. Blood glucose was measured on the day of blood collection by the enzymatic colorimetric method using glucose oxidase. Total cholesterol and triacylglycerol concentrations were measured by commercially available enzymatic reagents (Pars Azmoon, Tehran, Iran) adapted to selectra autoanalyser. HDL cholesterol was measured after precipitation of the apo B-containing lipoproteins with phosphotungistic acid. LDL-C was calculated according to the Friedewald method (Friedewald et al. 1972). Inter- and intra-assay CV were 1.6 and $0.6 \%$ for triacylglycerol. Blood pressure was measured twice after the participants had sat for $15 \mathrm{~min}$ (Azizi et al. 2002). Additional covariate information regarding age, smoking habits (Azizi et al. 2003), physical activity (Mirmiran et al. 2003), medical history and current use of medications (Azizi et al. 2003) was obtained using validated questionnaires, completed during the screening and every 2 weeks, as mentioned earlier. Physical activity was assessed by the Lipid Research Clinic questionnaire (Ainsworth et al. 1993).

Lipoprotein particle size was estimated by non-denaturing polyacrylamide gradient gel electrophoresis using the Krauss \& Burke (1982) method. Briefly, $5 \mathrm{ml}$ serum were electrophoresed (PS-250; Hybaid, Lexington, KY, USA) for $24 \mathrm{~h}$ at $125 \mathrm{~V}$ (on $2-16 \%$ for LDL and $4-25 \%$ for HDL) polyacrylamide gradient gels $(90 \mathrm{mmol} / \mathrm{l}$ Tris, $80 \mathrm{mmol} / 1$ boric acid, $3 \mathrm{mmol} / \mathrm{l}$ EDTA, pH 8.3). Gels were pre-run at $125 \mathrm{~V}$ for $15 \mathrm{~min}$ prior to loading samples. The gel was fixed in $50 \%$ methanol containing $10 \%$ acetic acid and Coomassie Brilliant Blue R250. The lane containing the calibrators (high-molecular weight standards) was stained with Coomassie Brilliant Blue R-250 and was destained with $20 \%$ methanol plus $9 \%$ acetic acid; for lipid staining, gradient gels were stained with $0.04 \%$ Oil Red 0 (Sigma) in $60 \%$ ethanol at $55^{\circ} \mathrm{C}$ and destained with $10 \%$ acetic acid and finally were scanned using a Helena Gel scanner (Junior 24; Helena, Beaumont,
France). The non-denaturing polyacrylamide gradient gel electrophoresis was done on the basis of the Krauss \& Burke (1982) method, and for calibration, in each run, the gels contained the calibrators (high-molecular weight standards containing thyroglobulin dimer, thyroglobulin and ferritin). So on the basis of the standard curve the sample lipoprotein sizes were determined. This method cannot determine the size of HDL subfractions $3 a, 3 b$ and $3 c$; it can determine HDL subfraction $2 \mathrm{a}$ and the majority of HDL subfraction 2b. It means HDL size relates to HDL subfraction $2 b$ size in the present study. Inter- and intra-assay $\mathrm{CV}$ were 8 and $5 \%$ for LDL size and 6 and $7 \%$ for HDL size, respectively.

\section{Statistical methods}

One-way ANOVA and $\chi^{2}$ tests were used to determine the significance of any baseline differences between groups. We compared data at base line, after 6 weeks and again after 12 weeks, separately for each diet, by using repeated measurement ANOVA. Comparison between the changes of the two groups also was assessed by between-group analyses in the repeated measurement ANOVA. Differences in lipid responses were evaluated in different weight status by Student's $t$ test. The outcome measures were the changes in lipoprotein particle size from the end of the run-in to the end of the intervention. All analyses were conducted using SPSS version 9.0 (SPSS Inc., Chicago, IL, USA).

\section{Results}

The mean age and BMI of adolescents were 14.5 (SD 1.2) years and $26 \cdot 3(\mathrm{SD} 4 \cdot 2) \mathrm{kg} / \mathrm{m}^{2}$. Table 2 shows the baseline characteristics of the subjects. Baseline characteristics of these adolescents did not differ significantly across the NCEP step II and control diet groups. Table 3 shows the mean changes of the serum lipids, lipoproteins and size of lipoproteins in the NCEP step II diet and control diet, after 6 weeks and 12 weeks, compared with baseline evaluations. Significant reductions in total cholesterol $(P<0.03)$ and LDL-C $(P<0.02)$ were seen among adolescents who consumed the NCEP step II diet. The NCEP step II diet significantly increased LDL-C particle size. Fig. 1 shows the mean change (and 95\% CI) of total cholesterol, LDL, HDL, triacylglycerol and size of lipoproteins. The NCEP step II diet resulted in higher decrease in total cholesterol $(-13$ (SD 4) v. -2 (SD 0.3) mg/dl, $P<0.001)$, LDL ( -9 (SD 2$) v$. $3(\mathrm{SD} 0.6) \mathrm{mg} / \mathrm{dl}, P<0.001)$ and higher increase in the size of the LDL (1.7 (SD 0.4) v. 0.1 (SD 0.4) nm, $P<0.001$ ). Weight and physical activity did not change significantly during the study period.

The prevalence of hypercholesterolaemia decreased significantly $(P<0.05)$ in the NCEP step II group $(68 \%$ in NCEP step II $v .100 \%$ in the control group) after 3 months. There was no significant difference in lipid response or lipoprotein particle size in normal and overweight children.

\section{Discussion}

The results of the present study which was conducted in hypercholesterolaemic adolescents showed that the NCEP step II diet had a favourable effect on LDL particle size, such that the mean diameter of LDL changed from the 
Table 2. Descriptive data of adolescents at baseline, according to the diet groups $\dagger$

\begin{tabular}{|c|c|c|c|c|c|c|}
\hline & \multicolumn{2}{|c|}{$\begin{array}{l}\text { National Cholesterol } \\
\text { Education Program } \\
\text { step II diet }(n 22)\end{array}$} & \multicolumn{2}{|c|}{ Control diet $(n 22)$} & \multicolumn{2}{|c|}{ All $(n 44)$} \\
\hline & Mean & SD & Mean & SD & Mean & SD \\
\hline Age (years) & $14 \cdot 4$ & $1 \cdot 2$ & $14 \cdot 6$ & 1.2 & 14.5 & 1.2 \\
\hline BMI $\left(\mathrm{kg} / \mathrm{m}^{2}\right)$ & $26 \cdot 4$ & $4 \cdot 3$ & $26 \cdot 2$ & $4 \cdot 2$ & $26 \cdot 3$ & $4 \cdot 2$ \\
\hline Systolic blood pressure (mmHg) & 113 & 20 & 110 & 19 & 112 & 19 \\
\hline Diastolic blood pressure $(\mathrm{mmHg})$ & 71 & $8 \cdot 0$ & 69 & 7.5 & 70 & $8 \cdot 0$ \\
\hline \multicolumn{7}{|l|}{ Female } \\
\hline$n$ & 11 & & 11 & & 22 & \\
\hline$\%$ & 50 & & 50 & & 50 & \\
\hline \multicolumn{7}{|l|}{ Physical activity (\%) } \\
\hline Very light & $60 \cdot 0$ & & $60 \cdot 1$ & & $60 \cdot 0$ & \\
\hline Light & 40 & & 39.9 & & $40 \cdot 0$ & \\
\hline \multicolumn{7}{|l|}{ Education (\%) } \\
\hline Junior high school & 50 & & 50 & & 50 & \\
\hline High school & 50 & & 50 & & 50 & \\
\hline
\end{tabular}

†For details of diets, see Table 1.

medium to the large category. Therefore, dietary habit may influence LDL size distribution. Other factors that are suggested to explain as much as half of the variation in LDL size distribution are genetic factors, adiposity and hormonal status (Greon et al. 1994; Krauss \& Dreon, 1995; Krauss, 2001). However, the present study discussed the role of one of the environmental factors, diet. Cross-sectional and dietary intervention studies reported an increase in small dense LDL with increasing carbohydrate intake (Kratz et al. 2002) and a slight shift to smaller LDL particle size when MUFA or PUFA replaced saturated fatty acids in healthy men (Gill et al. 2003). Of course there were some differences in the results of interventional and crossover studies, which might be due to the different designs, or the kind of saturated fatty acid intake (milk products, meat or poultry, etc.), and levels of serum cholesterol. Sjogren et al. (2004) showed that saturated fatty acid intake from milk products was associated with more favourable change in the LDL size profile. However, mildly hypercholesterolaemic men responded with an increase in smaller LDL subfractions when substituting saturated fatty acids for MUFA. The results of Sjogren et al. (2004) showed that dietary intervention on hypercholesterolaemic subjects might be more effective. There are some trials on the effect of diet on LDL particle size, however, the present study, according to our knowledge, is the first study to evaluate the influence of the NCEP step II diet on lipoprotein size in hypercholesterolaemic adolescents. The beneficial effects of the NCEP step II diet on lipoprotein level had previously been shown, but the present study presents results regarding the size of lipoproteins.

Fibre content of the NCEP step II diet was higher than the control diet which could explain its beneficial effects on lipid concentrations and particle size to some extent.

Regarding HDL particle size, significant changes were not seen after intervention, which may be due to lack of classification for HDL and were judged based on only the mean diameter of the HDL.

Regarding HDL concentration, the NCEP step II diet did not change HDL levels, which was similar to results of some previous studies (Schaefer et al. 1995; Flynn et al. 1999) but was in contrast

Table 3. Cardiovascular risk factors of adolescents at baseline, after 6 weeks and after 12 weeks of intervention, by diet groups $\dagger$ (Mean values and standard deviations)

\begin{tabular}{|c|c|c|c|c|c|c|c|c|c|c|c|c|c|c|}
\hline & \multicolumn{6}{|c|}{ Control } & \multicolumn{7}{|c|}{$\begin{array}{c}\text { National Cholesterol Education Program } \\
\text { step II diet }\end{array}$} & \multirow[b]{3}{*}{$P \S$} \\
\hline & \multicolumn{2}{|c|}{ Baselineł } & \multicolumn{2}{|c|}{ After 6 weeks } & \multicolumn{2}{|c|}{$\begin{array}{l}\text { After } 12 \\
\text { weeks }\end{array}$} & \multirow[b]{2}{*}{$P \S$} & \multicolumn{2}{|c|}{ Baseline } & \multicolumn{2}{|c|}{ After 6 weeks } & \multicolumn{2}{|c|}{$\begin{array}{l}\text { After } 12 \\
\text { weeks }\end{array}$} & \\
\hline & Mean & SD & Mean & SD & Mean & SD & & Mean & SD & Mean & SD & Mean & SD & \\
\hline Weight $(\mathrm{kg})$ & $63 \cdot 0$ & 6 & $62 \cdot 5$ & 6 & $62 \cdot 3$ & 6 & NS & 63.2 & 6 & $63 \cdot 1$ & 6 & 63.0 & 6 & NS \\
\hline Fasting blood sugar (mg/dl) & 100 & 23 & 101 & 23 & 106 & 24 & NS & 103 & 24 & 102 & 24 & 101 & 24 & NS \\
\hline Total cholesterol (mg/dl) & 221 & 24 & 220 & 24 & 219 & 23 & NS & 219 & 24 & 212 & 22 & 206 & 20 & 0.03 \\
\hline Triacylglycerol (mg/dl) & 197 & 23 & 199 & 23 & 200 & 24 & NS & 195 & 22 & 192 & 21 & 190 & 20 & NS \\
\hline LDL-C (mg/dl) & 141 & 16 & 142 & 16 & 144 & 17 & NS & 143 & 17 & 139 & 16 & 134 & 15 & 0.02 \\
\hline HDL-C (mg/dl) & 38 & 9 & 37 & 9 & 38 & 9 & NS & 39 & 9 & 37 & 8 & 36 & 8 & NS \\
\hline LDL-C particle size $(\mathrm{nm})$ & $26 \cdot 2$ & $3 \cdot 3$ & $26 \cdot 3$ & $3 \cdot 2$ & $26 \cdot 3$ & $3 \cdot 3$ & NS & $26 \cdot 2$ & 3.5 & $27 \cdot 0$ & 3.6 & $27 \cdot 9$ & 3.9 & 0.03 \\
\hline HDL-C particle size (nm) & $9 \cdot 3$ & $1 \cdot 8$ & $9 \cdot 2$ & $1 \cdot 8$ & $9 \cdot 1$ & 1.7 & NS & $9 \cdot 3$ & 1.7 & 9.4 & 1.8 & 9.5 & 1.8 & NS \\
\hline
\end{tabular}

HDL-C, HDL cholestrol; LDL-C, LDL cholestrol.

†For details of procedures and diets, see p. 000 and Table 1.

$\ddagger$ Baseline values are not significantly different among different diet groups.

$\S P$ values are resulted from repeated measurements ANOVA among baseline, after 6 weeks and after 12 weeks. 

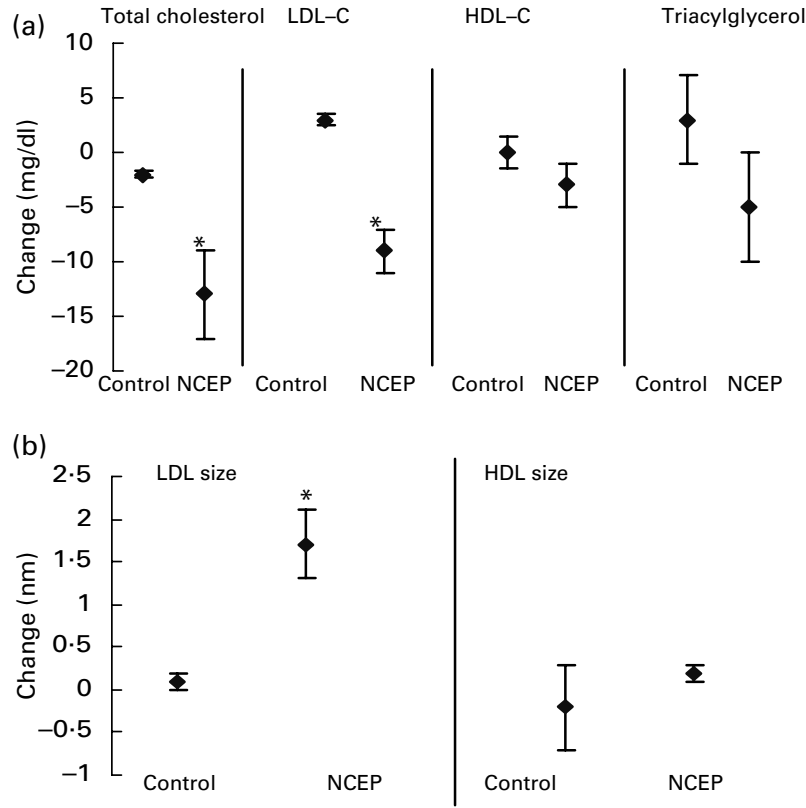

Fig. 1. Change in (a) total cholesterol, LDL cholestrol (LDL-C), HDL cholestrol (HDL-C) and triacylglycerols and (b) size of lipoproteins for control diet and the National Cholesterol Education Program (NCEP) step II diet. For details of procedures, see p. 000 . Values are means with their $95 \% \mathrm{Cl}$ depicted by vertical bars. Mean values were significantly different from those of the control group: ${ }^{*} P<0.001$

to some others (Wood et al. 1991; Walden et al. 2000). It seems that different patterns of LDL size distributions and overall lipoprotein concentrations might be responsible for the differences in results of various studies; of course it should be kept in mind that age factors in the present study (adolescence) might be the cause for the difference in results. The biological mechanism whereby a NCEP step II diet may exert a favourable effect on the LDL particle size might be dependent on LDL concentrations. This favourable effect was seen in the present study with hypercholesterolaemic subjects; however, since we were unable to separate the subfractions of LDL and HDL and reported only the mean diameter of lipoproteins, this was a limitation of the present study. Another limitation was the inability to report the amount of trans-fatty acid intake, in two groups separately, since transfatty acid analysis was not included in the software analysis adapted for the population in the present study. Thirdly, in the present study, actual food was not provided to subjects and only diet was prescribed. Using an appropriate control group, matched to the intervention group for confounding variables, is the strength of the present study.

It is concluded that a NCEP step II diet not only reduces the serum LDL concentration of hypercholesterolaemic adolescents but also has a favourable effect on the LDL particle size distribution. The precise related mechanism needs to be studied in future experimental designs.

\section{Acknowledgements}

We express our gratitude to all participants of the study and also the staff of Endocrine Research Center for their efforts in conducting the study.

\section{References}

Ainsworth BE, Jacobs JR \& Leon AS (1993) Validity and reliability of self-reported physical activity status: the Lipid Research Clinics questionnaire. Med Sci Sports Exerc 25, 92-98.

Akerblom HK, Viikari J, Uhari M, et al. (1984) A study of cardiovascular risk factors and their determinants in Finnish children. Ann Clin Res 16, 23-33.

Azizi F, Emami H, Salehi P, Ghanbarian A, Mirmiran P \& Mirbolooki M (2003) Cardiovascular risk factors in the elderly: the Tehran Lipid and Glucose Study. J Cardiovasc Risk 10, 65-73.

Azizi F, Ghanbarian A, Madjid M \& Rahmani M (2002) Distribution of blood pressure and prevalence of hypertension in Tehran adult population: Tehran Lipid and Glucose Study (TLGS), 19992000. J Hum Hypertens 16, 305-312.

Azizi F, Rahmani M, Emami H \& Majid M (2000) Tehran Lipid and Glucose Study rationale and design. CVD Prevention 3, 242-247.

Azizi F, Rahmani M, Madjid M, Allahverdian S, Ghanbili J, Ghanbarian A \& Hajipour R (2001) Serum lipid levels in an Iranian population of children and adolescents: Tehran Lipid and Glucose Study. Eur J Epidemiol 17, 281-288.

Boreham C, Savage JM, Primrose D, Cran G \& Strain J (1993) Coronary risk factors in schoolchildren. Arch Dis Child 68, $182-186$.

Chapman MJ, Laplaud PM, Luc G, Forgez P, Bruckert E, Goulinet S \& Lagrange D (1988) Further resolution of the low density lipoprotein spectrum in normal human plasma: physicochemical characteristics of discrete subspecies separated by density gradient ultracentrifugation. J Lipid Res 29, 442-458.

Flynn MM, Zmuda JM, Milosavljevic D, Caldwell MJ \& Herbert PN (1999) Lipoprotein response to a National Cholesterol Education Program step II diet with and without energy restriction. Metabolism 48, 822-826.

Friedewald WT, Levy RI \& Fredrickson DS (1972) Estimation of the concentration of low-density lipoprotein cholesterol in plasma, without use of the preparative ultracentrifuge. Clin Chem 8, 499-502.

Gill JM, Brown JC, Caslake MJ, Wright DM, Cooney J, Bedlford D, Hughes DA, Stanley JC \& Packard CJ (2003) Effects of dietary monounsaturated fatty acids on lipoprotein concentration, compositions, and subfraction distributions and on VLDL apolipoprotein B kinetics: dose-dependent effects on LDL. Am J Clin Nutr 78, $47-56$.

Greon DM, Fernstrom HA, Miller B \& Krauss RM (1994) Low-density lipoprotein subclass patterns and lipoprotein response to a reduced fat diet in men. FASEB $J \mathbf{8}, 121-126$.

Institute of Medicine, Food and Nutrition Board (2002) Dietary Reference Intake for Energy, Carbohydrate, Fiber, Fat, Fatty Acids, Cholesterol, Protein, and Amino Acids. Washington, DC: The National Academies Press.

Kannel WB \& Wilson PW (1992) Efficacy of lipid profiles in prediction of coronary disease. Am Heart J 124, 768-774.

Knutsen SF \& Knutsen R (1991) The Tromso Survey: the Family Intervention study - the effect of intervention on some coronary risk factors and dietary habits, a 6-year follow-up. Prev Med 20, 197-212.

Kojima M, Kanno H, Yamazaki Y, Koyama S, Kanazawa S \& Arisaka O (2005) Association of low-density lipoprotein particle size distribution and cardiovascular risk factors in children. Acta Paediatr 94, 281-286.

Kratz M, Gulbahce E, von Eckardstein A, Cullen P, Cignarella A, Assmann G \& Wahrburg U (2002) Dietary mono- and polyunsaturated fatty acids similarly affect LDL size in healthy men and women. $J$ Nutr 132, 715-718.

Krauss RM (2001) Dietary and genetic effects on low-density lipoprotein heterogeneity. Аnпи Rev Nutr 21, 283-295. 
Krauss RM \& Burke DJ (1982) Identification of multiple subclasses of plasma low density lipoproteins in normal humans. J Lipid Res 23, 97-104.

Krauss RM \& Dreon DM (1995) Low-density-lipoprotein subclasses and response to a low-fat diet in healthy men. Am J Clin Nutr $6 \mathbf{6 2}$, 478S-487S.

Krummel DA, Mahan LK \& Escott-Stump S (2004) Medical nutrition therapy in cardiovascular disease. In Krause's Food, Nutrition and Diet Therapy, 11th ed. Philadelphia: WB soundess. p. 871.

Lamarche B, Lemieux I \& Despres JP (1999) The small, dense LDL phenotype and the risk of coronary heart disease: epidemiology, pathophysiology and therapeutic aspects. Diabetes Metab 25, 199-211.

Lamarche B, Moorjani S, Cantin B, Dagenais GR, Lupien PJ \& Despres JP (1997) Associations of HDL2 and HDL3 subfractions with ischemic heart disease in men. Prospective results from the Quebec Cardiovascular Study. Arterioscler Thromb Vasc Biol 17, $1098-1105$.

Lindgren FT, Jensen LC, Wills RD \& Freeman NK (1969) Flotation rates, molecular weights and hydrated densities of the low-density lipoproteins. Lipids 4, 337-344.

Mietus-Snyder M, Baker AL, Neufeld EJ, Roberts C, Dermarkarian S, Beiser AS \& Newburger JW (1993) Effects of nutritional counseling on lipoprotein levels in a pediatric lipid clinic. Am J Dis Child 147, 378-381.

Mirmiran P, Azadbakht L \& Azizi F (2005) Dietary quality-adherence to the dietary guidelines in Tehranian adolescents: Tehran Lipid and Glucose Study. Int J Vitam Nutr Res 75, 195-200.

Mirmiran P, Mohammadi F, Allahverdian S \& Azizi F (2003) Estimation of energy requirements for adults: Tehran Lipid and Glucose Study. Int J Vitam Nutr Res 73, 193-200.

Plaza I, Mariscal RP, Ros-Jellici J, et al. (1989) The Fuenlabrada study: lipids and lipoproteins in children and adolescents. Rev Esp Cardiol 42, 444-458.
Schaefer EJ, Lichtenstein AH, Lamon-Fava S, Contois JH, Li Z, Rasmursen H, McNamara JR \& Ordovas JM (1995) Efficacy of a National Cholesterol Education Program Step 2 diet in normolipidemic and hypercholesterolemic middle-aged and elderly men and women. Arterioscler Thromb Vasc Biol 15, $1079-1085$.

Sempos CT, Cleeman JI, Carroll MD, et al. (1993) Prevalence of high blood cholesterol among US adults. An update based on guidelines from the second report of the National Cholesterol Education Program Adult Treatment Panel. JAMA 269, 3009-3014.

Sjogren P, Rosell M, Skoglund-Andersson C, et al. (2004) Milkderived fatty acids are associated with a more favorable LDL particle size distribution in healthy men. $J$ Nutr 134, 1729-1735.

Skoglund-Andersson C, Tang R, Bond MG, de Faire U, Hamsten A \& Karpe F (1999) LDL particle size distribution is associated with carotid intima-media thickness in healthy 50-year-old men. Arterioscler Thromb Vasc Biol 19, 2422-2430.

Sun Z, Welty FK, Dolnikowski GG, Lichtenstein AH \& Schaefer EJ (2001) Effects of a National Cholesterol Education Program Step II Diet on apolipoprotein A-IV metabolism within triacylglycerol-rich lipoproteins and plasma. Am J Clin Nutr 74, 308-314.

Walden CE, Retzlaff BM, Buck BL, Wallick S, McCann BS \& Knopp RH (2000) Differential effect of National Cholesterol Education Program (NCEP) Step II diet on HDL cholesterol, its subfractions, and apoprotein A-I levels in hypercholesterolemic women and men after 1 year: the beFIT Study. Arterioscler Thromb Vasc Biol 20, 1580-1587.

Wood PD, Stefanick ML, Williams PT \& Haskell WL (1991) The effects on plasma lipoproteins of a prudent weight-reducing diet, with or without exercise, in overweight men and women. $N$ Engl J Med 325, 461-466. 